\title{
CONCEPTUAL MODEL FOR MANAGEMENT OF DIGITAL FACTORY SIMULATION INFORMATION
}

\author{
Ayadi, M. ${ }^{* * *}$; Costa Affonso, R. ; Cheutet, V. ${ }^{*}$; Masmoudi, F. ${ }^{* *}$; Riviere, A. ${ }^{*} \&$ Haddar, M. ${ }^{* *}$ \\ *LISMMA / SUPMECA, 3 rue Fernand Hainaut, 93407 Saint-Ouen Cedex, France \\ ${ }^{* *}$ U2MP/ENIS, B.P 1173, w.3038 Sfax, Tunisia \\ E-Mail: mohamed.ayadi@supmeca.fr, roberta.costa@supmeca.fr, vincent.cheutet@supmeca.fr, \\ faouzi.masmoudi@enis.rnu.tn, alain.riviere@supmeca.fr,mohamed.haddar@enis.rnu.tn
}

\begin{abstract}
Digital Factory (DF) aims at proposing simulation tools to design a product and its production system in parallel. Nevertheless, DF is marked by the multiplicity and heterogeneity of simulation models that are used, that slows down its usage in industry. We propose in this paper a conceptual model to manage the different simulation information created and manipulated through a DF project. This model is based on an analysis of the current design strategies and the used simulation tools. Finally, an industrial application has been developed to validate the completeness of this model.

(Received in August 2012, accepted in November 2012. This paper was with the authors 1 month for 2 revisions.)
\end{abstract}

Key Words: Design Methodology, Digital Factory, Information Management, Manufacturing and Simulation Model

\section{INTRODUCTION}

The industrial competition and the products complexity push the industrial companies to develop and to adopt new design methods. Industrial Companies must improve their production process and reduce their production cost since $85 \%$ of product costs are engaged during the design phase.

One solution is the use of concurrent engineering [1]. This is a strategic concept leading to the systematic approach dealing with integration of all aspects of the product lifecycle constraints (included manufacturability, assembly and reparability considered at the earlier phases of the design process).

DF is in this case a powerful method composed of a set of software tools and methodologies offering the design, the simulation, the initiation and the optimization of production systems $[2,3]$.

Issued from concurrent engineering and Computer Integrated Manufacturing (CIM) the DF approach aims to reduce the validation loops by ensuring the integration of the product manufacturability and producibility with business constraints as soon as possible.

By simulation all activities of a factory, the DF allows the identifications of problems related to production processes and helps to product or production process changes for a more efficient production [4]. The DF approach can also help to reduce the time-to-market to lower efforts and to eliminate handling errors.

Companies are increasingly using simulations transforming their production processes by integrating simulation in the adopted methodology of design and validation [5].

Despite the existence of many simulation tools integrating DF, their implementation in companies is until now not enough and does not fully satisfy the needs of the industrials [6, 7]. Several issues explain the roots of this situation: (1) DF is intrinsically complex, due to the different levels of detail co-existing (from the operation on a specific station to the global supply chain) and to the variety of simulation type (prescriptive vs. based on events [8]) and 
(2) Different actors in the company, with very different point of view are interacting in the DF scope: designer, agent of simulation production and manufacturer.

Due to simulation complexity new techniques of management are needed [9]. We target in this paper to develop a conceptual model dedicated to the management of DF simulation information. This model has to take into account the variety of simulations implied in DF, the diversity of actors and the information flows between them, as well as the interactions between the DF environments and other phases of product lifecycle, the system information is proposed by consequence.

In order to identify the interactions of PDP and DF we do analyse in section 2 an overview of design methodologies commonly used in industry. A diversity of simulations used in DF is analysed and two cartographies of actual and proposed simulation tools are introduced in section 3. A conceptual model for simulation information management is proposed in section 4. The validation of the architecture and an industrial application are made in section 5 while the conclusion and perspectives are in section 6 .

\section{THE ENGINEERING DESIGN PROCESS}

It is important to analyse the Design Theories and Methodologies (DTM) to identify the interactions between the PDP and DF. In [10] the authors propose a complete review of DTM currently developed and used in industry and teaching. Considering this research work, our analysis is also based on a framework which has been generated to define the boundaries of the design process phases, highlighting the commonalities and differences between each phase [11]. In this work, three families of DTM are proposed: systematic design, integrated design and simulation-based design (SBD). The grouping is based on similarities of actors, interaction in PDP, the importance of simulations and types of information flows.

\subsection{Systematic design family}

One of the most popular methodologies of systematic design is proposed by [12]. The lifecycle process is identified by functions, not by processes. This idea changes the ordinary view of the design process i.e. objectives are important but not the way to fulfil them. In their model, the design process is decomposed further into four main phases: Planning and clarification of the tasks, conceptual design, embodiment design and detail design. Methodologies such as the VDI (The Association of the German engineers) [13], integrated design [14] or Engineering System [15] can be included in this category. These various approaches are focused on the product development. The development phase of production is also treated, but only in the end of detail design. This generates considerable downtime during the launch of the production, due to the number of redesign iterations. Indeed these iterations have an impact on the time-to-market, and the development and manufacturing of the product. Another inconvenient of this methodology is that the information of customers and the resources are not mentioned in the design process.

\subsection{Integrated design family}

Integrated design family groups DTM that considers a form of actors' collaboration through the insertion of specific constraints in the designer's activity. Product design has indeed a considerable effect on product properties in every phase of the lifecycle of the product. This requires the integration of lifecycle constraints during its development. This integration helps to develop better products in terms of requirements fulfilment, cost, quality and development time [16-18]. It involves the simultaneous consideration of design characteristics and constraints, some of them imposed by manufacturing. In general, product lifecycle constraints 
are considered during the embodiment and detailed design phases. The objectives are to avoid redesign loops and to integrate manufacturing information into the design process as early as possible.

Many design methodologies can be included in this category. We can refer to Integrated Product Development [17], Design For Manufacturing (DFM), axiomatic design [19], setbased design [20], etc. Integrated design does not consider the issue of simulation in their model. The growing complexity of products requires the use of simulation to show in detail the various scenarios and choose the best solution.

\subsection{Simulation based design family}

The Simulation Based Design (SBD) concept refers to the use of simulations during the whole product lifecycle. The objective is to validate the behaviour of the product during its lifecycle. It can be implemented by the integration of new digital technologies and new methodologies [21]. Other work aims to facilitate the integration of design and manufacturing modelling at the concept design stage, including cost [22]. In particular, this methodology allows easiest exploitation of digital manufacturing simulation capabilities.

These various approaches emphasise the simulation of product to be developed by taking into account some simple constraints of the product lifecycle. This methodology does not integrate the product development phase (analysis of task, conceptual and embodiment design etc.) in the simulation one.

\subsection{Synthesis}

The development process described in these DTM should not be considered in two parts: the product development process and the production development process. Indeed, it should be considered as a whole, to really integrate the correlations between the product and its production system. To achieve such an objective, even if tools dedicated for product simulation and production simulation exist to date, we need a framework to manage the global development process and the information flow feeding this process. At this end, we propose to first analyse the existing tools and methods in DF.

\section{CARTOGRAPHY OF DF SIMULATION TOOLS}

In this section, we present the current DF state of art and introduce proposed cartographies of simulation tools used in DF.

DF concept is defined as an integrated approach to improve the product and its production engineering processes, by the use of simulation [23]. Simulation is a key technology and can be applied in virtual models on various information levels and stages to improve the factory planning $[24,25]$. The objective is to design and optimize the development of product in a collaborative environment concurrently with its production engineering.

To support such approach, a large diversity of simulation tools exists [8]. It is thus possible to realise a flow simulation at the level of a production line, in order to define the stock level necessary to obtain a satisfying customer performance, or to realise the offline programming of a robotic cell, part of the same production line. This purpose is achieved by series of tools, such as 3D modelling programs or simulation programs.

Nevertheless the tools of DF are based on a PPR (Product, Processes, and Resources) philosophy. Process is represented by a suite of operations, in which are specified the resources (tools, robot, machine tool etc.). The international standards provide several definitions for the Product, Process and Resources (ISO/CEN 19439, ISO 10303-49, ISO 15531-1, ISO 18629-1, etc.). Even if the differences are quite small, their existence proves the 
difficulty to obtain a consensus over these concepts. For this paper, we propose to use these definitions, coming from the ISO:

- Product: A thing or substance produced by an artificial process,

- Process: Structured set of activities or sub-processes, involving various enterprise entities, that is designed and organized for a given purpose,

- Resource: Device, communication network, equipment, human or material used in and/or controlling a process.

Fig. 1 proposes two cartographies of DF simulation tools. The first one analyses the existing tools, and the second one presents our proposed cartography. For that purpose, three axes are considered, which represent three primary aspects of the simulation capabilities.

The first simulation axis represents the capacity of tools to integrate data from product, process and/or resource. This is especially important in DF to secure the information of products and processes during an early phase of development and also to follow-up the evolution of products and production with the use of digital models [2].

The second simulation axis is the integration of PDP phases. To create this axis, we adopted the four phases considered by [12], mentioned above: analysis of task, conceptual design, embodiment design and detailed design. This choice is motivated by the fact that most of the design methodologies adopt the same phases with different nomination and in a different order of design phase's launch.

The third simulation axis is the ability to vary the level of details of the simulation as required throughout the virtual representation of the lifecycle. We have adopted the six levels of details of the DF proposed by the projects DF [6] and DF 2 [8], corresponding to an aeronautic vision of the extended enterprise (Fig. 2). These levels correspond to specific needs for the design and simulation of the production system behaviour, and so to specific actors of the production system development process, with their own tools and methodologies.
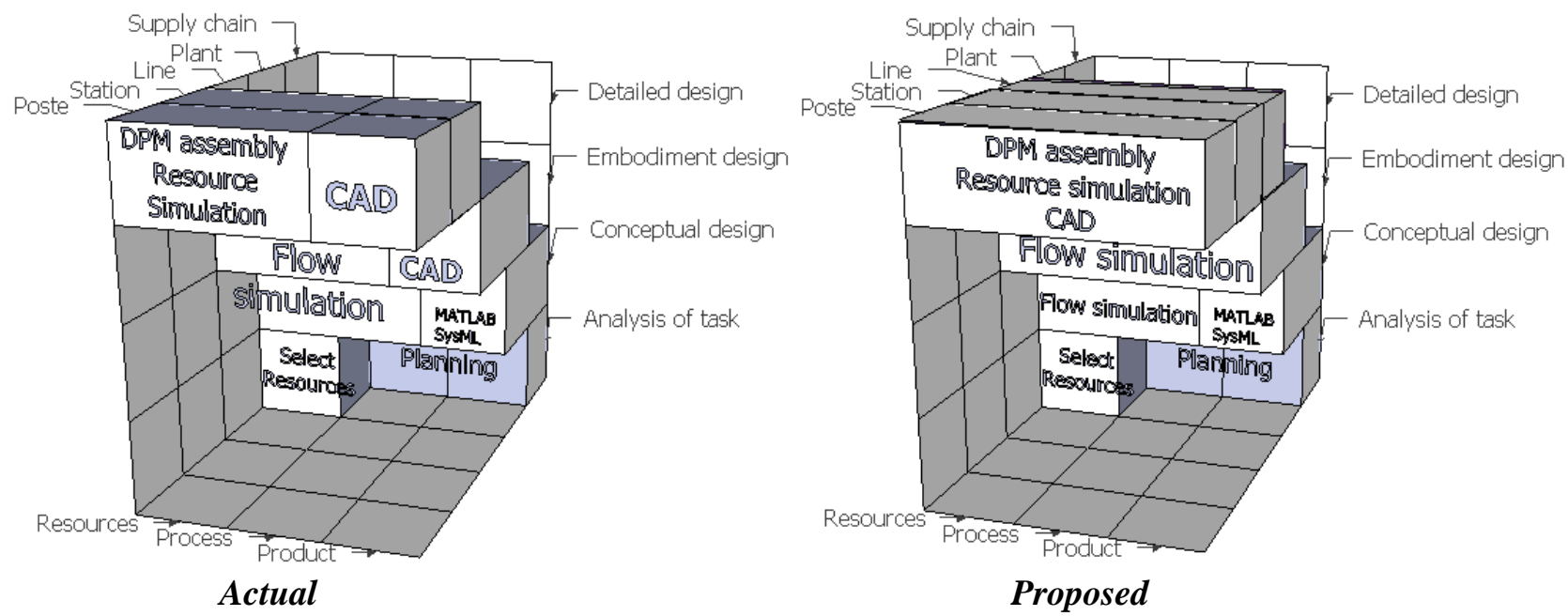

Figure 1: Actual and proposed cartography of simulation tools in DF.

The current cartography (Fig. 1) demonstrates the lack of interactions between the different simulation tools. For instance, at each phase and each detail, there is a clear separation between the tools acting on the product and the ones acting on process and resources. This separation is reflected in the figure by the vertical line separating the product of processes and resources during the detailed design phase. This creates a gap in the PPR integration: with the current tools, every time a designer makes a change on the product, there is no effect on the simulation of production process and all the process of production simulation must be repeated. 
Moreover, there is a clear breakdown between tools acting during the embodiment phase at the line level and the ones acting during the detailed design at the station level. This breakdown implies a large information gap that will be complex to fill in order to ensure the continuity of information flow over all the PDP.

In summary, in DF scope, many software solutions based on CAX are already available for product related to their environment, but dedicated for the most part to detailed design phase. Nevertheless, the main issue is not the existence of adequate tools but their capability to communicate between them and ensure a global consistency of the product and its production system during the early stages of product design.

Very few works propose a solution to enhance the communication between simulation tools. Most of them are dedicated to Computer Aided Engineering, i.e. product simulation behaviour, like [26-28]. Only the approach described in [29] has been proposed within the DF, but they do not tackle the problem of multiple actors in DF.

As a consequence, the objective of this work is to propose a conceptual model for managing simulation information in DF as early as possible in the PDP.

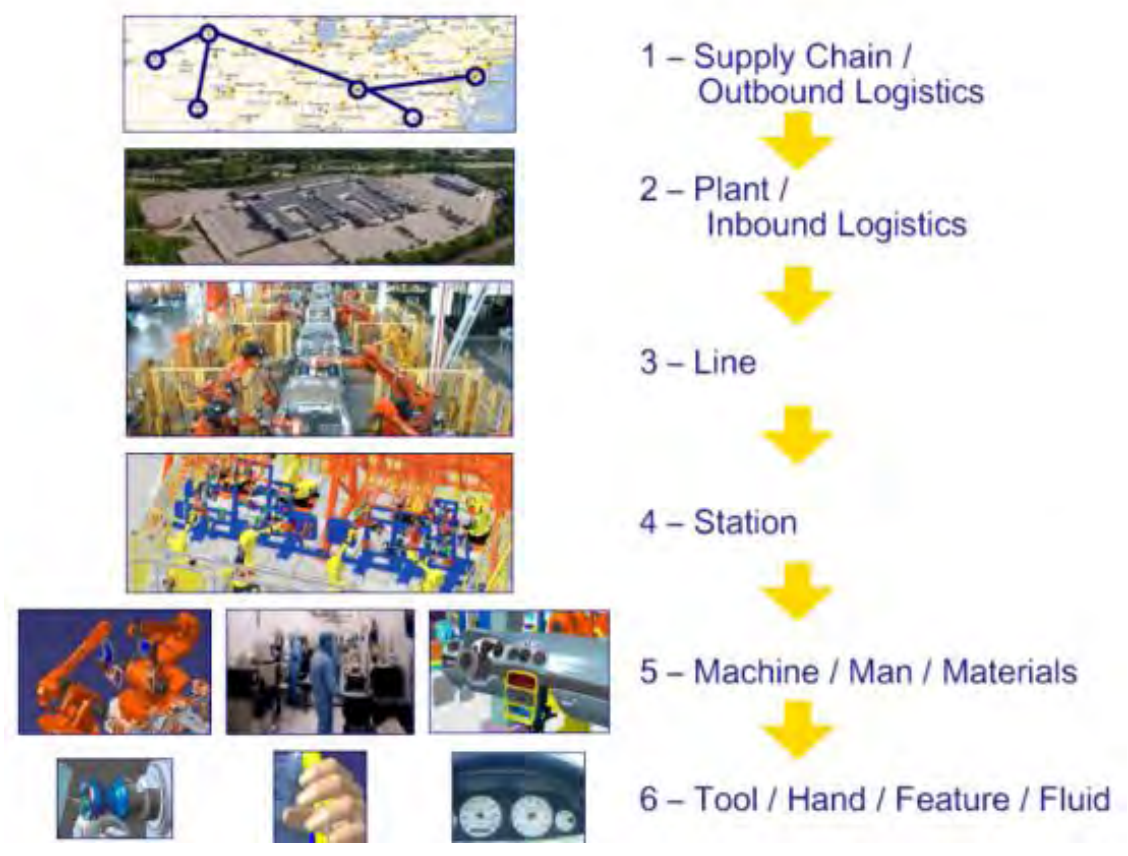

Figure 2: Different layers in the DF [8].

\section{DEVELOPMENT OF A CONCEPTUAL MODEL FOR MANAGING SIMULATION INFORMATION IN DIGITAL FACTORY}

A system that supports simulation information should be able to integrate the information related to the product and the process using the resource data, which are all in different formats (Fig. 3). The simulation captures not only this information, but contains the relationships between them. In fact, to act as a central element between product and resource, the process element has to be specified in detail. From a technical point of view, different data structures of process type have to be differentiated [25].

The agents of DF simulations need to explore three information models to support global coordination decisions: product information model, manufacturing (and production) information model and order information model. Fig. 3 illustrates the main functions and the information flows when simulation agents use three information models to support decisionsmaking. The solid arrows indicate that the simulation agents get the required information and 
knowledge from three views; the dashed arrows indicate the simulation results information. The colour of arrows indicates the specific information and knowledge classes and its result after simulation.

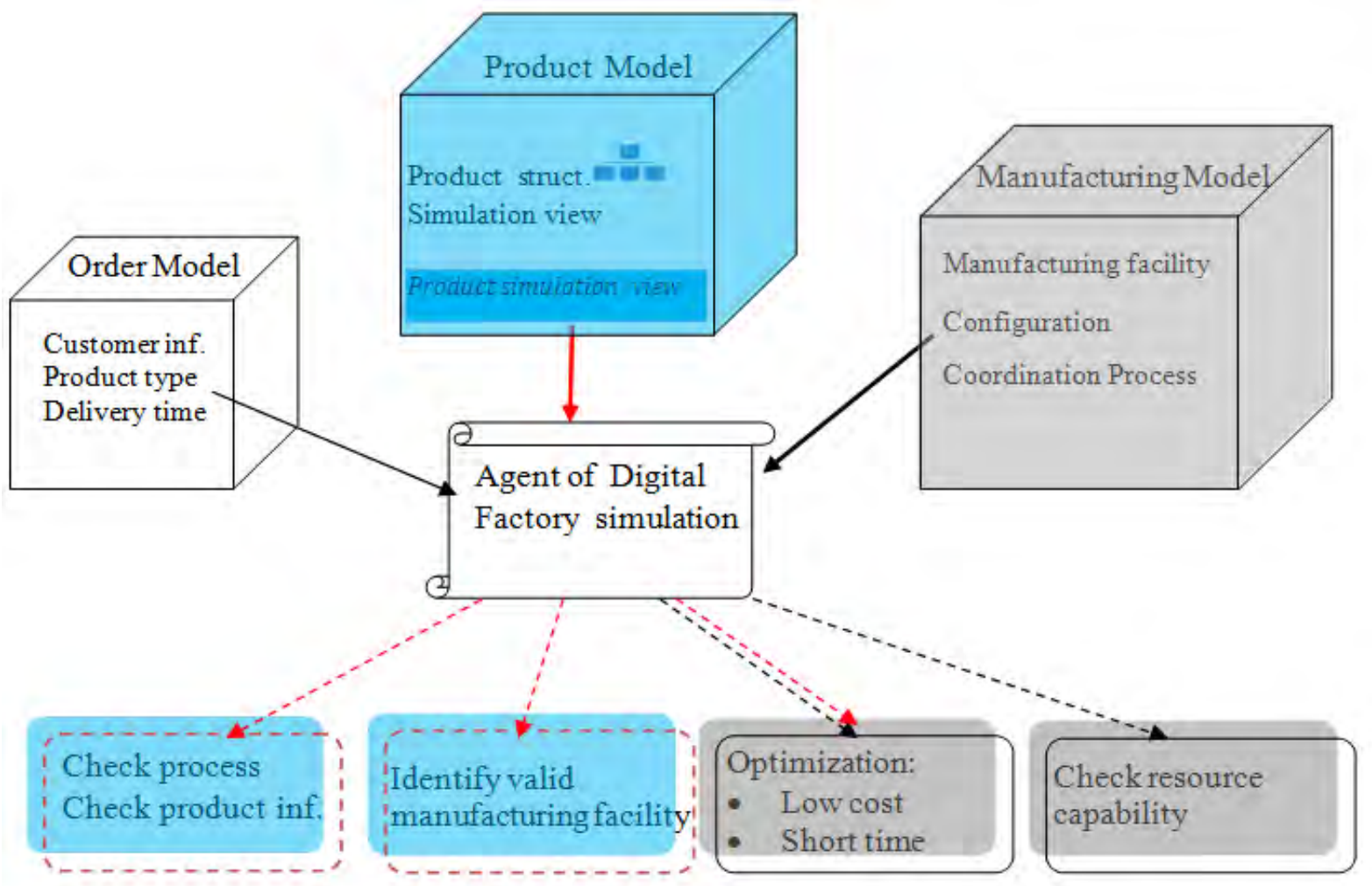

Figure 3: Information flows in a simulation process.

The following sections will only discuss two information models (product and manufacturing) and their relationship. Thereafter a simulation model is drawn. The order model is regarded as information or a constraint to be taken into account during product development.

\subsection{Information view definition}

The PDP can be considered as the results of several viewpoints trying to collaborate to satisfy the requirements of each stakeholder. We define in this paper the concept of view as the cognitive scheme of a specific actor of the PDP, implying specific representations for data and information to be understood.

In [30] the authors analyse the design and manufacturing views and their interactions in order to propose a framework supporting multiple viewpoint information integration. According to our research objective, we base our conceptual model on their approach and add the specificities of simulation information (especially DF one), which are missing in their proposition.

As a consequence, Fig. 4 illustrates three views considering a metallic tank design and production. In this example, the consumer product designer considers the metallic tank by taking into account its functionality, characteristics and the customer requirements. The tank designer performs the design and determines the manufacturing process, i.e. the welding process, the rolling technique, etc. Further, the tank manufacturer considers the preparation of the production, like the association of manufacturing operations to station and operators for instance, with the objective to ensure an adequate production for a good product as early as possible. 


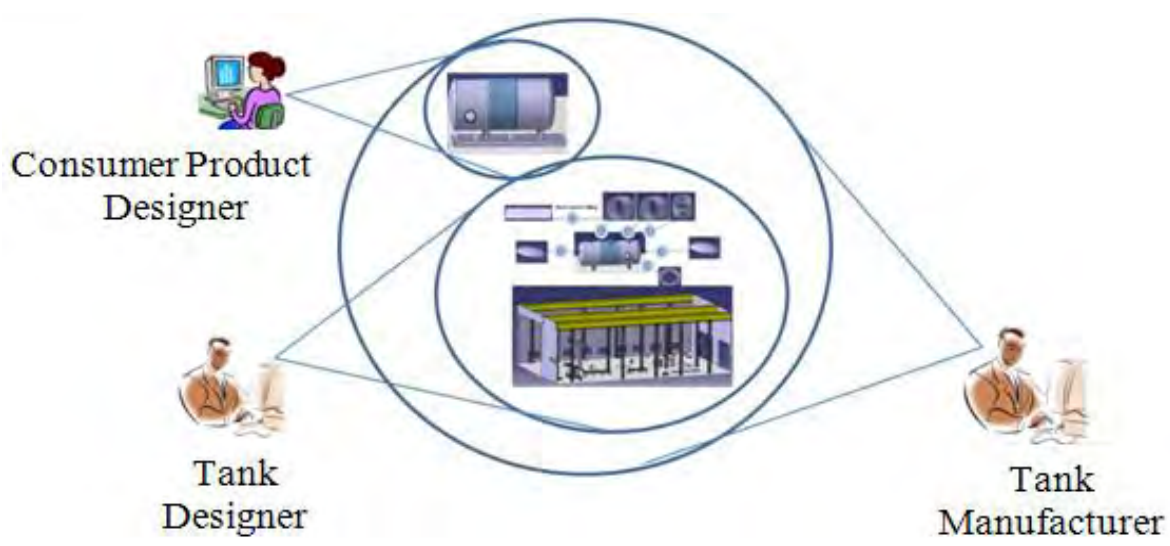

Figure 4: Example of multiple views.

In the next section, we propose to enrich the product and manufacturing information model proposed by [30] in order to support information required for DF simulations.

\subsection{Product and manufacturing information model}

The concepts of Product and Manufacturing models are defined as a type of information Models [31]. In the standard ISO10303-1994, information model is defined as a formal model of a bordered set of facts, concepts or instructions, to meet a specific requirement. There are other research works who define this product and manufacturing model [32-35], but none of them includes the concept of simulation model, which is also a type of information model.

In Fig. 5, the authors of [31] propose a "Product" class, with whom five classified classes are linked with aggregation relationships. In particular, this structure elicits some subclasses of the "View" class, allowing the definition of different views during the PDP.

Better than using the "Other View" class, we define a "Product Simulation View" class, which represents the product and manufacturing information needed to make a simulation. This information is taken from the product model information such as the chosen process, the general shape of product, orders of assembly, the selection of resource etc.

The structure of "product simulation view" class can be further developed to capture low-level information. In Fig. 5, we so define the "Product simulation" class and the "P. Manufacturing simulation view" one. The first class is proposed to capture information that facilitates decision-making during the product development process, e.g. order of assembly, function simulation etc. The second class is designed to link information between the product and their production process and represent the product information needed to make simulation.

Moreover, we choose as manufacturing model the one proposed in [36]. This model, which stands for how the resources and processes are used, captures information relating to four major aspects of the enterprise, i.e. the processes, resources, strategies and views. In particular, the "Views" class is related to the "Facility" class with aggregation relationship to propose different views of the facility according to the level of detail and the different alternatives proposed.

We propose to enrich this "View" class with the class of M-Manufacturing simulation view that captures all the manufacturing information needed for simulation. Examples of information captured from manufacturing simulation view in manufacturing model can be: plan layout, organization of workshops, arrangement of machines, etc.

In Fig. 5, the classes in gray represent our contribution to both information models. These classes support information necessary to carry out the simulation, which is an inevitable tool for the product development in digital factory. 


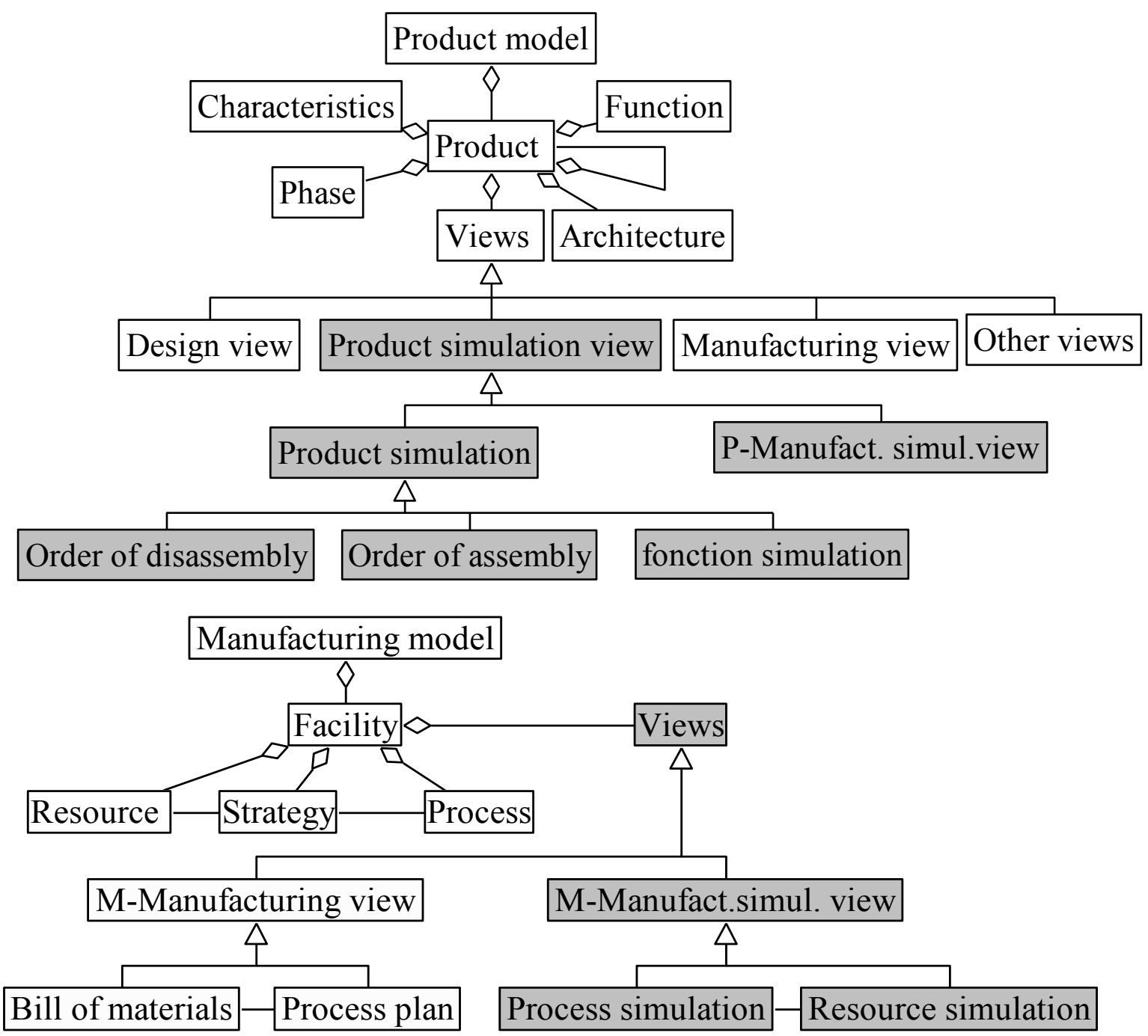

Figure 5: Top-level classes of product and manufacturing information with some subclasses of the view class (in white, classes coming from [31,36]; in grey, added classes).

\subsection{Modelling relationships between product and manufacturing information models}

The study of relationships between information required for simulation, taken from product and manufacturing model, is crucial. In fact, for an integrated approach of product development, we should ensure that these two types of information can work together in the same environment in order to help making the right decision at the right time.

We so propose in Fig. 6 the Digital Factory class, as an aggregation of the product information and M-manufacturing one.

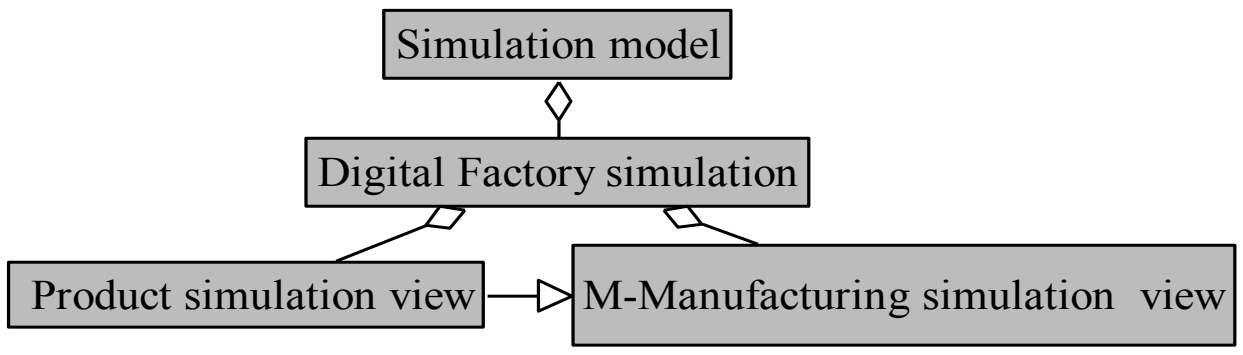

Figure 6: Relationship between product, manufacturing and simulation model information. 
The manufacturing model maintains all manufacturing process information for all products whereas the product model needs only specific manufacturing process information for product fulfilment. For this reason, there are one-way interactions from the product model to the manufacturing model [35-37]. This means that communication between product properties and global manufacturing capabilities can only begin with product information. We can found appropriate manufacturing process information, resource information etc. from product characteristics information. Hence, the manufacturing model cannot be the origin of the communication with the product model.

\section{APPLICATION ON AN INDUSTRIAL USE CASE}

In a first time, we propose to validate the completeness of our proposed model, before developing the information system based on it. To achieve such objective, we apply our model to an industrial use case, which is a metal construction manufacturing. During the project, all the data and information collected and generated have been integrated in the conceptual model and we search for lacks in the models.

We concentrate our study on one department of the company, which was the assembling metal tank (standard EN 12285-2). The objective is to ameliorate the configuration of the manufacturing process for such products, and reduction of the production-time is the most important performance indicator for comparing the manufacturing system modification propositions.

We adopted the following methodology:

1. an analysis of the current situation has been first performed and a collection of data and information has been obtained. This stage has been realised by a study of the real plant and interviews with company's experts,

2. from the initial situation, simulation models have been created to model the current behaviours of production processes and resource systems, with the objective to validate the adequacy between the virtual factory and the real one and so ensure the consistency of further simulations,

3. after analysis of interviews and simulations, we have proposed a solution to improve the production system. This solution has been exploited in the simulation models to prove the added-value and the production-time reduction,

4. finally, we have formulated a set of specifications of the proposed solution, using the simulations as communication media too.

We illustrate in Fig. 7 an example of product simulation information: the digital description of the product assembly process without the assignment of resources available in the plant. The numbering follows the order of metal tank assembling process. An example of $\boldsymbol{P}$-Manufacturing simulation information is the routings of the assembly process, with adequate stations assigned. Lastly, an example of M-manufacturing simulation view is the complete assembly process in the virtual factory environment.

Fig. 7 also illustrates an example of information navigation between sub-classes of product simulation view and M-manufacturing simulation view. In this use case, we separate the transformations of information views from product model to manufacturing model into three transformation types:

1. the product simulation information is first transformed into the P-manufacturing simulation one: for instance, we associate to the assembly process the adequate stations, with possible loops of process validation. This type of transformations illustrates the navigation of information between views in the same model and as a consequence, this transformation is a knowledge-based transformation [31], 
2. the P-manufacturing simulation view is then transformed into the M-manufacturing simulation view: for instance, the stations are located in the plant layout. This type of transformation illustrates the navigation of information between two different models,

3. the three views are finally integrated, to realize the simulation of process assembly in a digital environment. This type of transformation illustrates the needs for maintaining links between the views, to perform modifications and improvements in shorter cycles.

Simulations have been used to test new machines, layout and products, to optimize systems, to increase productivity, quality and customer satisfaction, and to make predictions and reliable decisions. By using the simulation tools, we verified that we can reduce the production time by $30 \%$ [39].

After this use case, we can highlight three main results about information integration and simulation models, which validate the completeness of our proposition:

- the navigation of information from one view to another in the same model may be considered as an enrichment of information model necessary to fulfil the simulation of the factory,

- the complex relationship has been established on the P-Manufacturing Simulation view class under the Product Simulation View in the product model and the $\mathbf{M}$ Manufacturing Simulation view class under the View class in the manufacturing model (transformation 2). The navigation of information between the views of two different model is really an information conversion from specific model information towards a general one,

- to achieve simulations, we merge the information needed for simulation, coming from the product and manufacturing information models. This conceptual model supports the integration of simulation information in product lifecycle.

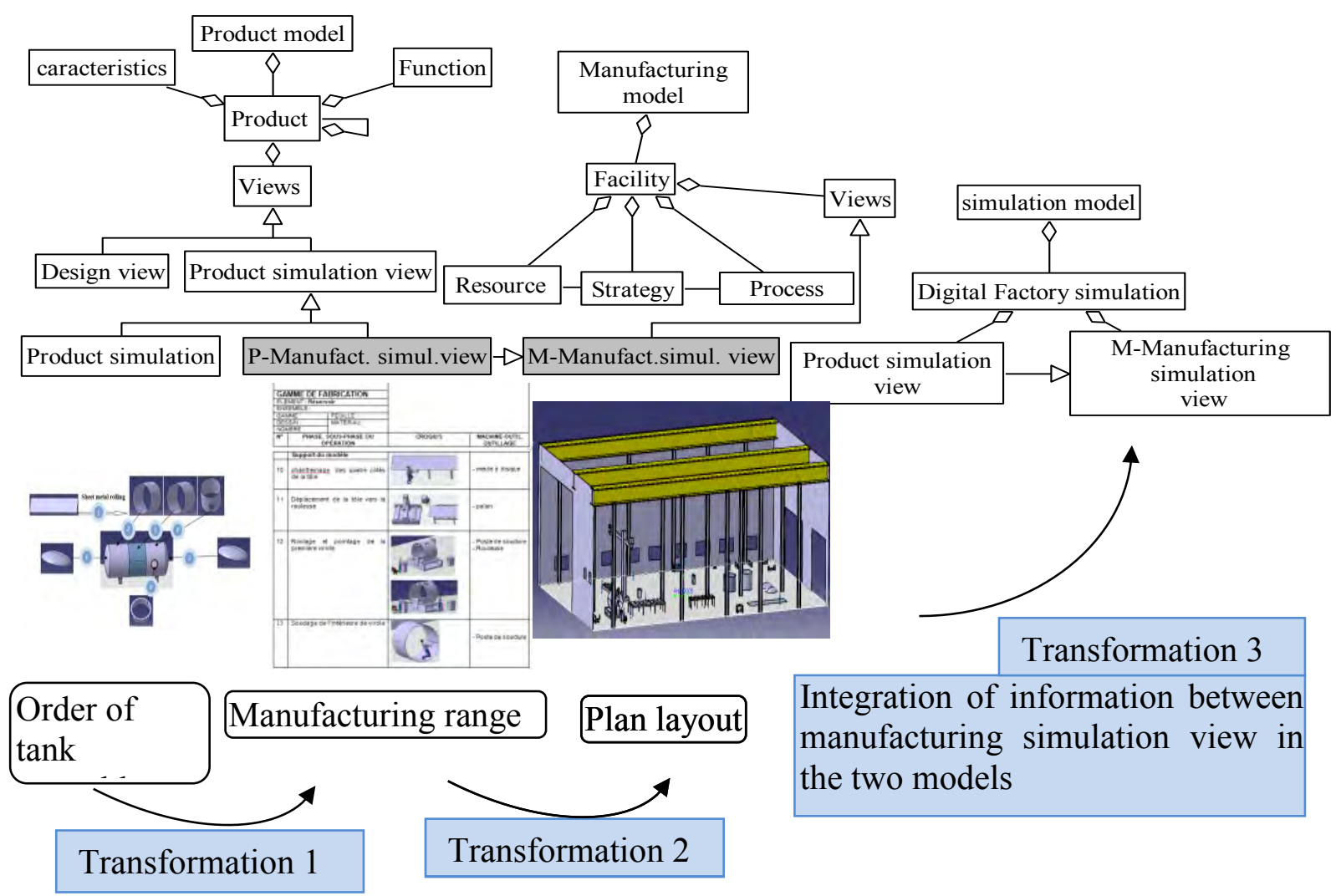

Figure 7: Information integration between views in product and manufacturing model. 


\section{CONCLUSION AND FUTURE WORK}

DF concept aims at adopting an integrated approach to optimize the product and its production process. The early integration of product development in production planning offers considerable savings in time and in cost, because a larger part of product costs is determined in the early phases of the product development. The key concept is here the usage of digital simulations to design the product and its production system at different stages of the PDP. A large variety of simulation tools exist to implement this strategy but we enlighten a lack of data and information management in DF area, lack that limits its benefits and its diffusion in industry.

To overcome this lack, this paper presents a conceptual model that supports simulation information management between two views: product view and manufacturing one. With knowledge and information transformation associated to the views, we introduce the new concept of simulation model, which consists of an integration of information coming from PManufacturing Simulation View and M-Manufacturing Simulation View classes. The information transformations between views are not possible without the knowledge of relationships between views.

The conceptual model has been tested with success on an industrial use case to validate the completeness of our proposition. This study supports the integration of information of multiple viewpoints of product and production environment.

Future work will focus on the development of an information system based on this conceptual model. To achieve such objective, we propose to use the MERISE methodology [40]. Once the information system developed, we will test our approach on a more complex industrial use case coming from an aeronautical partner [41].

\section{REFERENCES}

[1] Coze, Y.; Kawski, N.; Kulka, T.; Sire, P.; Sottocasa, P.; Bloem, J. (2009). Virtual concept > real profit with digital manufacturing and simulation, Dassault Systèmes and Sogeti

[2] Bracht, U.; Masurat, T. (2005). The Digital Factory between vision and reality, Computers in Industry, Vol. 56, No. 4, 325-333, doi:10.1016/j.compind.2005.01.008

[3] Kühn, W. (2006). Digital Factory- Integration of Simulation enhancing the Product and Production Process towards Operative Control and Optimisation, International Journal of Simulation, Vol. 7, No. 7, 27-39

[4] Arndt, F. W. (2006). The Digital Factory - Planning and simulation of production in automotive industry, Braz, J. et al. (eds.), Informatics in control, automation and robotics I, Springer, Dordrecht, 27-29

[5] Nagalingam, S. V.; Lin, G. C. I. (2008). CIM - still the solution for manufacturing industry, Robotics and Computer-Integrated Manufacturing, Vol. 24, No. 3, 332-344, doi:10.1016/j.rcim. $\underline{2007.01 .002}$

[6] Boime, B. (2005). Le projet Usine numérique: Un projet du pôle de compétitivité SYSTEM@TIC Paris Région, Revue internationale d'ingénierie numérique, Vol. 1, No. 4, 393402

[7] Wiendahl, H.-P.; Elmaraghy, H. A.; Nyhuis, P.; Zäh, M. F.; Wiendahl, H.-H.; Duffie, N.; Brieke, M. (2007). Changeable Manufacturing - Classification, Design and Operation, CIRP Annals Manufacturing Technology, Vol. 56, No. 2, 783-809, doi:10.1016/j.cirp.2007.10.003

[8] Cheutet, V.; Lamouri, S.; Paviot, T.; Derroisne, R. (2010). Consistency management of simulation information in Digital Factory, $8^{\text {th }}$ International Conference of Modeling and Simulation, Hammamet, 9 p.

[9] Hägele, J.; Hänle, U.; Kropp, A.; Streit, M. (2010). The CAE-Bench project - A web-based system for data, documentation and information to improve simulation processes, from: http://www.mscsoftware.com/support/library/conf/auto00/p03300.pdf, accessed in March 2010 
[10] Tomiyama, T.; Gu, P.; Jin, Y.; Lutters, D.; Kind, C.; Kimura, F. (2009). Design methodologies: Industrial and educational applications, CIRP Annals - Manufacturing Technology, Vol. 58, No. 2, 543-565, doi:10.1016/j.cirp.2009.09.003

[11] Howard, T. J.; Culley, S. J.; Dekoninck, E. (2008). Describing the creative design process by the integration of engineering design and cognitive psychology literature, Design Studies, Vol. 29, No. 2, 160-180, doi:10.1016/j.destud.2008.01.001

[12] Pahl, G.; Beitz, W.; Feldhusen, J.; Grote, K. (1975). Engineering Design - A Systematic Approach, Springer, Berlin

[13] VDI 4499 (2006). Digital factory Fundamentals. Resource document, from: www.vdi.de, accessed in March 2006

[14] Ulrich, K.; Eppinger, S. (2004). Product Design and Development, $3^{\text {rd }}$ ed., McGraw-Hill, New York

[15] INCOSE - International Council on Systems Engineering (2012). What is Systems Engineering?, from: http://www.incose.org/practice/whatissystemseng.aspx, accessed in April 2012

[16] Swift, K. G.; Booker J. D. (2003). Process Selection: From Design to Manufacture, $2^{\text {nd }}$ ed., Butterworth-Heinemann, Oxford

[17] Andreasen, M.; Hein, L. (1987). Integrated product development, Springer Verlag, New York

[18] Ferrer, I.; Rios, J.; Ciurana, J.; Garcia-Romeu, M. L. (2010). Methodology for capturing and formalizing DFM Knowledge, Robotics and Computer-Integrated Manufacturing, Vol. 26, No. 5, 420-429, doi:10.1016/j.rcim.2009.12.003

[19] Suh, N. P. (2005). Complexity: Theory and Applications, Oxford University Press, Oxford

[20] Sobek, D. K.; Ward, A. C.; Liker, J. K. (1999). Toyota's Principles of Set-Based Concurrent engineering, Sloan Management Review, Vol. 40, No. 2, 67-83

[21] Bossak, M. A. (1998). Simulation based design, Journal of Materials Processing Technology, Vol. 76, No. 1-3, 8-11, doi:10.1016/S0924-0136(97)00308-7

[22] Curran, R.; Gomis, G.; Castagne, S.; Butterfield, J.; Edgar, T.; Higgins, C.; McKeever, C. (2007). Integrated digital design for manufacture for reduced life cycle cost, International Journal of Production Economics, Vol. 109, No. 1-2, 27-40, doi:10.1016/j.ijpe.2006.11.010

[23] Chen, D. (2009). Information Management for the Factory Planning Process, Licentiate Thesis, Production Engineering, The Royal Institute of Technology, Stockholm

[24] White, L. R. (2012). A hierarchical production planning system simulator, International Journal of Simulation Modelling, Vol. 11, No. 1, 40-57, doi:10.2507/IJSIMM11(1)4.199

[25] Bley, H.; Franke, C. (2004). Integration of Product Design and Assembly Planning in the Digital Factory, Institute for Production Engineering/CAM Saarland University, Germany, 6 p.

[26] Joshi, A. A. (2004). CAE data management using traditional PDM systems, Proceedings of ASME 2004 Design Engineering Technical Conferences, Salt Lake City

[27] SIMULIA (2007). The case for Simulation Lifecycle Management - SLM whitepaper, from: http://www.simulia.com/products/slm.html, accessed in September 2011

[28] Song, I.-H.; Yang, J.; Jo, H.; Choi, S. (2009). Development of a lightweight CAE middleware for CAE data exchange, International Journal of Computer Integrated Manufacturing, Vol. 22, No. 9, 823-835, doi:10.1080/09511920902866088

[29] Fortin, C.; Huet, G. (2007). Manufacturing Process Management: iterative synchronisation of engineering data with manufacturing realities, International Journal of Product Development, Vol. 4, No. 3-4, 280-295, doi:10.1504/IJPD.2007.012496

[30] Gunendran, A. G.; Young, R. I. M. (2006). An information and knowledge framework for multiperspective design and manufacture, International Journal of Computer Integrated Manufacturing, Vol. 19, No. 4, 326-338, doi:10.1080/09511920500399508

[31] Costa, C. A.; Young, R. I. M. (2001). Product range models supporting design knowledge reuse, Journal of Engineering Manufacture, Vol. 215, No. 3, 323-337, doi:10.1243/0954405011515406

[32] Valentan, B.; Brajlih, T.; Drstvensek, I.; Balic, J. (2011). Development of a part-complexity evaluation model for application in additive fabrication technologies, Strojniski vestnik-Journal of Mechanical Engineering, Vol. 57, No. 10, 709-718, doi:10.5545/sv-jme.2010.057

[33] Krause, F.-L.; Kimura, F.; Kjellberg, T.; Lu, S. C.-Y.; et al. (1993). Product Modelling, CIRP Annals - Manufacturing Technology, Vol. 42, No. 2, 695-706, doi:10.1016/S0007-8506(07) 62532-3 
[34] McKay, A.; Erens, F.; Bloor, M. S. (1996). Relating product definition and product variety, Research in Engineering Design, Vol. 8, No. 2, 63-80, doi:10.1007/BF01607862

[35] Liu, S.; Young, R. I. M. (2007). An exploration of key information models and their relationships in global manufacturing decision support, Journal of Engineering Manufacture, Vol. 221, No. 4, 711-724, doi:10.1243/09544054JEM531

[36] Sliskovic, D.; Grbic, R.; Hocenski, Z. (2011). Online data preprocessing in the adaptive process model building based on plant data, Technical Gazette, Vol. 18, No. 1, 41-50

[37] Logozar, R. (2012). Algorithms and data structures for the modelling of dynamical systems by means of stochastic finite automata, Technical Gazette, Vol. 19, No. 2, 227-242

[38] Molina, A.; Bell, R. (1999). A manufacturing model representation of a flexible manufacturing facility, Journal of Engineering Manufacture, Vol. 213, No. 3, 225-246, doi:10.1243/ 0954405991516723

[39] Ayadi, M.; Costa Affonso, R.; Cheutet, V.; Masmoudi, F.; Riviere, A.; Haddar, M. (2011). Proposition d'un modèle d'intégration des simulations pour l'UN, 7ieme Conference CPI, Oujda, Morocco

[40] Nanci, D.; Espinasse, B. (1996). Ingénierie des systèmes d'information, Merise, Deuxième génération, $3^{\text {rd }}$ ed., Sybex, Paris

[41] Cheutet, V.; Lamouri, S.; Derroisne, R. (2011). Proposition of a framework for consistency management between digital factory simulations, Proceedings of International Conference on Industrial Engineering and Systems Management (IESM'11), Metz, 497-506 